\title{
Bacteremia among Children Admitted to a Rural Hospital in Kenya
}

\author{
James A. Berkley, M.D., Brett S. Lowe, M.Phil., Isaiah Mwangi, M.B., B.Ch., \\ Thomas Williams, Ph.D., Evasius Bauni, M.Sc., Saleem Mwarumba, H.N.D., \\ Caroline Ngetsa, H.N.D., Mary P.E. Slack, F.R.C.Path., Sally Njenga, H.N.D., \\ C. Anthony Hart, F.R.C.Path., Kathryn Maitland, Ph.D., Mike English, M.D., \\ Kevin Marsh, F.R.C.P., and J. Anthony G. Scott, M.R.C.P.
}

\section{ABSTRACT}

\section{BACK GROU N D}

There are few epidemiologic data on invasive bacterial infections among children in sub-Saharan Africa. We studied every acute pediatric admission to a rural district hospital in Kenya to examine the prevalence, incidence, types, and outcome of community-acquired bacteremia.

\section{METHODS}

Between August 1998 and July 2002, we cultured blood on admission from 19,339 inpatients and calculated the incidence of bacteremia on the basis of the population served by the hospital.

\section{RESULTS}

Of a total of 1783 infants who were under 60 days old, 228 had bacteremia (12.8 percent), as did 866 of 14,787 children who were 60 or more days of age (5.9 percent). Among infants who were under 60 days old, Escherichia coli and group B streptococci predominated among a broad range of isolates (14 percent and 11 percent, respectively). Among infants who were 60 or more days of age, Streptococcus pneumoniae, nontyphoidal salmonella species, Haemophilus influenzae, and E. coli accounted for more than 70 percent of isolates. The minimal annual incidence of community-acquired bacteremia was estimated at 1457 cases per 100,000 children among infants under a year old, 1080 among children under 2 years, and 505 among children under 5 years. Of all in-hospital deaths, 26 percent were in children with community-acquired bacteremia. Of 308 deaths in children with bacteremia, 103 (33.4 percent) occurred on the day of admission and 217 (70.5 percent) within two days.

\section{CONCLUSIONS}

Community-acquired bacteremia is a major cause of death among children at a rural sub-Saharan district hospital, a finding that highlights the need for prevention and for overcoming the political and financial barriers to widespread use of existing vaccines for bacterial diseases.
From the Centre for Geographic Medicine Research (Coast), Kilifi, Kenya (J.A.B., B.S.L., I.M., T.W., E.B., S.M., C.N., S.N., K. Maitland, M.E., K. Marsh, J.A.G.S.); the Centre for Clinical Vaccinology and Tropical Medicine (J.A.B., B.S.L., K. Marsh, J.A.G.S.) and the Department of Paediatrics (M.E.), University of Oxford, Oxford, United Kingdom; the Health Protection Agency Haemophilus Reference Unit, John Radcliffe Hospital, Oxford, United Kingdom (M.P.E.S.); the Department of Microbiology, University of Liverpool, Liverpool, United Kingdom (C.A.H.); and the Department of Paediatrics and Wellcome Trust Centre for Clinical Tropical Medicine, Imperial College, London (K. Maitland). Address reprint requests to Dr. Berkley at P.O. Box 230, Kilifi, Kenya, or atjberkley@kilifi.mimcom.net.

N EnglJ Med 2005;352:39-47.

Coppright (c) 2005 Massachusetts Medical Society. 
$\mathrm{E}$

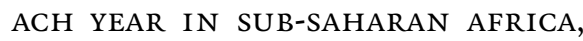
4.6 million children die before reaching the age of five years, ${ }^{1}$ and the vast majority of these deaths are not fully investigated. Most health facilities lack the resources for doing microbiologic studies, so the data on invasive bacterial infections are very limited. The local incidence of infections such as meningitis and pneumonia has been estimated, often in relation to vaccine studies. ${ }^{2}$ However, there are almost no estimates of incidence, mortality, or hospital burden for the majority of pathogenic bacterial species. Most data are from a few urban referral centers, ${ }^{3-9}$ with very little recent data from the rural areas ${ }^{10,11}$ where most people in sub-Saharan Africa live. Thus, the impact of childhood bacteremia is largely unknown. We aimed to establish a complete description of community-acquired bacteremia among children admitted to a rural Kenyan district hospital by investigating all acute admissions, without selection. We sought to determine the burden, incidence, and types of community-acquired bacteremia and the associated mortality. We also examined the association between bacteremia and two prevalent coexisting illnesses, malnutrition and infection by the human immunodeficiency virus (HIV). We report the results of a prospective study of 19,339 children during four years.

\section{METHODS}

\section{LOCATION}

Kilifi District Hospital is situated in a rural area on the Kenyan coast (Fig. 1). Children living in the district receive 10 to 100 mosquito bites infective for Plasmodium falciparum annually. Primary care facilities in the district are limited. Antibiotics and antimalarial drugs, including a combination of sulfamethoxazole and pyrimethamine, are available without prescription. Immunization with Haemophilus influenzae type $\mathrm{b}$ conjugate vaccine was introduced in November 2001. In 2000, 9.8 percent of women attending the hospital antenatal clinic were infected with HIV. ${ }^{12}$ Antiretroviral therapy was not in use during the study. Government-employed clinical officers in the outpatient department, working independently of the inpatient research team, referred children for admission.

\section{PATIENTS AND CLINICAL METHODS}

We recruited all children under the age of 13 years who were admitted to the hospital between $\mathrm{Au}$ - gust 1,1998 , and July 31, 2002, unless they were admitted for elective procedures or for observation after minor accidents. The study was explained to the parent or guardian of each child, and written informed consent was obtained. The Kenya Medical Research Institute/National Ethical Review Committee approved the study. Data were recorded on admission on standard forms. ${ }^{13}$ We defined young infants as those under 60 days old. ${ }^{14}$ Weight was measured with the use of an electronic scale (Weylux), which was checked weekly for accuracy and consistency. We calculated $z$ scores for weight according to age using American National Center for Health Statistics reference data (Epi Info, version 6.01). Malnutrition was defined as a weight-forage $z$ score of -3 or less or the presence of bilateral pedal edema (kwashiorkor). Patients with severe medical problems were defined as those who were admitted to the intensive care unit. (The intensive care unit was not equipped with mechanical ventilators.) Antibiotics and other treatments were given according to recommendations of the World Health Organization (WHO) ${ }^{4}$ and were subsequently modified by clinical response and laboratory results. Research clinicians provided around-the-clock clinical care.

\section{SAMPLING AND LABORATORY METHODS}

On admission, the child's skin was cleaned with 70 percent ethanol and allowed to dry before blood was drawn for culture, a complete blood count (Beckman Coulter), malaria testing, HIV serologic testing, and antimicrobial testing. Blood was inoculated into a culture bottle (BACTEC Peds Plus, Becton Dickinson) after the needle had been changed and the top had been cleaned with 70 percent ethanol and allowed to dry. Blood culture bottles were weighed before and after inoculation and processed with an automated blood-culture system (BACTEC 9050, Becton Dickinson). Positive blood and cerebrospinal fluid samples were cultured on standard mediums with the use of routine microbiologic techniques. A biochemical test kit (API, Biomerieux), serologic tests, or both were used to confirm suspected pathogens. Pneumococcal serotyping was performed with the use of the quellung reaction and $H$. influenzae serotyping by latex agglutination using polyclonal rabbit antiserum (Statens Seruminstitut and Difco Laboratories). The results of $H$. influenzae serotyping were confirmed by polymerase-chain-reaction (PCR)-based capsular genotyping with the use of primers designed to 
amplify the capsule type-specific regions of the cap loci in each of the six capsular $H$. influenzae types a through $\mathrm{f}^{15}$

Antibodies to HIV were tested by enzyme-linked immunosorbent assay (ELISA) (Vironostika, Biomerieux) and dipstick (Determine, Abbott Laboratories). Positive samples from children under 18 months of age and samples with discordant results were assayed by PCR for proviral DNA. ${ }^{16}$ Antimicrobial activity in plasma was determined with the use of a bioassay in which a filter paper disk containing $20 \mu \mathrm{l}$ of plasma was placed on a fully sensitive strain of Staphylococcus aureus (NCTC6571) on a nutrient agar plate, incubated overnight at $37^{\circ} \mathrm{C}$, and examined for a zone of inhibition, indicating antimicrobial activity. All laboratory procedures were internally controlled, and external quality monitoring was performed by the United Kingdom National External Quality Assessment Service.

\section{POPULATION OF CATCHMENT AREA}

In 2000, a demographic surveillance system was established to monitor a population of 189,148 people living in 23,549 households in an area of 706 $\mathrm{km}^{2}$ surrounding the hospital. Approximately 15 percent of births in the area occurred in Kilifi District Hospital. Using data from 2000 to 2003, we extrapolated age-specific population estimates to the midpoint of the study, accounting for the rates of birth, death, and migration. Incidence estimates were calculated with the use of data from patients with bacteremia who were residing within the surveillance area.

\section{STATISTICAL ANALYSIS}

Data analysis was performed with the use of Stata software (version 8.0). Categorical data were tested with Fisher's exact test and the chi-square test for trend. We used the Kruskal-Wallis test to compare the distributions of nonordinal data. Reported $\mathrm{P}$ values are two-tailed. We used logistic regression, adjusted for age, to examine the deaths of inpatients with potentially contaminated blood cultures. The effect on culture sensitivity of antimicrobial agents in the blood was estimated with the use of a case-control study among infants who were at least 60 days old and resided within the surveillance area. The 556 controls were randomly selected from among 15,476 patients who did not have bacteremia and were matched by age in two strata of the study group ( 2 to 17 months and 18 months or more) and by the severity of their illness (fatal, se-

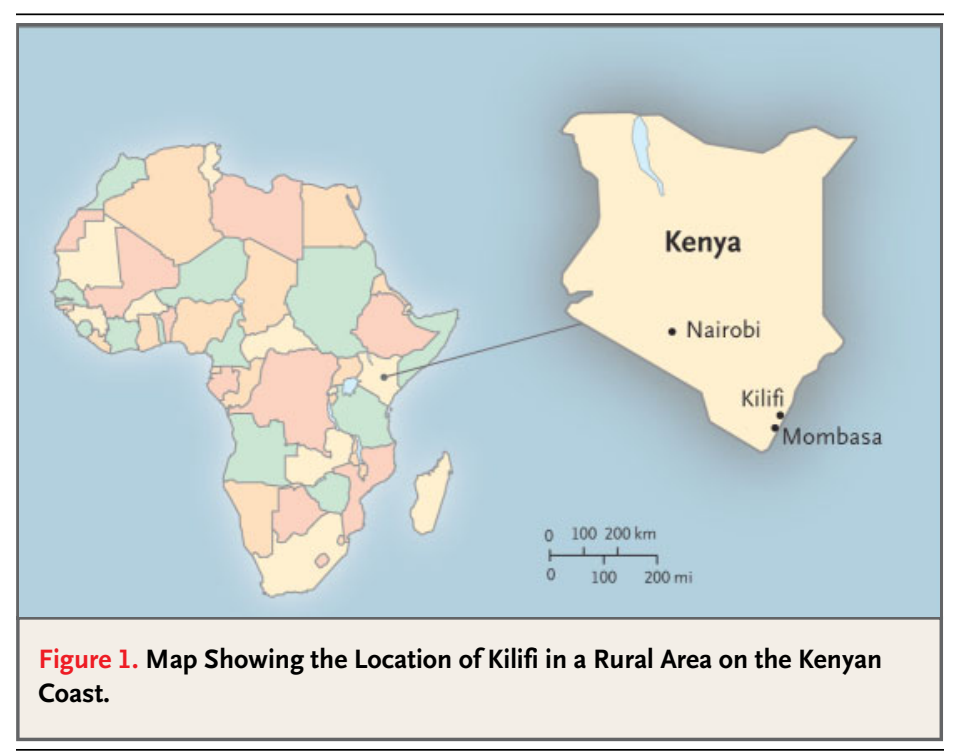

vere, or nonsevere) with 499 patients with bacteremia. We calculated the prevalence of antimicrobial use as a weighted average between strata and expressed the effects of antimicrobial drugs on culture positivity as odds ratios with 95 percent confidence intervals, using Cornfield's approximation. ${ }^{17}$

To evaluate the association between bacteremia and HIV infection, stored plasma samples from 1044 patients with bacteremia and 1037 randomly selected patients who did not have bacteremia, frequency-matched for age in three strata ( 0 to 59 days, 2 to 17 months, and 18 months or more), were tested for HIV. We analyzed these data, including individual anthropometric measurements, using logistic regression with adjustment for age.

\section{RESULTS}

During the study, 20,340 children were admitted to the hospital. We excluded 744 children who had nonacute medical problems (those admitted for elective procedures or for observation only), 90 who were admitted for acute medical problems but whose parent or guardian did not provide parental consent for participation in the study, 138 for whom blood cultures were not available, and 29 with inadequate records. Thus, 19,339 patients (98.7 percent of patients with acute medical problems) were included. Blood cultures from 2769 of those patients (14.3 percent) grew coagulase-negative staphylococci (1526 patients), bacillus (1162), micrococcus (52), or viridans streptococci (29). The proportion of patients with these isolates who died in the 
hospital was similar to that of all other admissions (age-adjusted odds ratio, 1.11; 95 percent confidence interval, 0.96 to 1.29$)$. These isolates were classified as contaminants, and since they may have masked a true infection, these patients were excluded from the analysis. Data from $16,570 \mathrm{pa}-$ tients with acute medical problems who had blood cultures that were definitely positive or negative were therefore entered into the main analysis. Of these patients, 14,518 were under the age of five years (87.6 percent), 2676 were admitted to the intensive care unit (16.1 percent), and 1184 died in the hospital (7.1 percent).

\section{PREVALENCE OF COMMUNITY-ACQUIRED BACTEREM IA}

Of the 16,570 patients whose results were analyzed, bacteremia was identified in 1094 (6.6 percent) (Table 1). Bacteremia occurred in 608 of 8945 boys ( 6.8 percent) and in 486 of 7625 girls ( 6.4 percent) $(\mathrm{P}=0.27)$. There was no evidence of variation in the overall prevalence of bacteremia according to age for patients who were more than a year old. Among infants admitted on the first day of life, 21 of 260 (8.1 percent) had bacteremia, as compared with 96 of 607 (15.8 percent) admitted on day 2 to day $6(\mathrm{P}=0.002)$. During the study, lumbar puncture was performed in 3810 children (23.0 percent), and cerebrospinal fluid cultures yielded an additional 22 isolates that were not identified by blood culture. The results of those cultures are not included here.

The median volumes of blood that were cultured were $1.2 \mathrm{ml}$ (interquartile range, 0.6 to 1.9 ) among patients who were at least 60 days old and $0.6 \mathrm{ml}$ (interquartile range, 0.2 to 1.3 ) among younger infants. The median volumes that were cultured among children at least 60 days old were $1.1 \mathrm{ml}$ among patients with fatal illness, $1.3 \mathrm{ml}$ among those with severe illness, and $1.2 \mathrm{ml}$ among those with medical problems that were not severe $(\mathrm{P}<0.001)$. Among children who were at least 60 days old, the proportion who had a positive blood culture increased with each milliliter of blood that was cultured (5.6 percent at $1 \mathrm{ml}, 6.8$ percent at $2 \mathrm{ml}$, and 7.9 percent at $3 \mathrm{ml} ; \mathrm{P}=0.006$ ). There was no significant trend among younger children. The proportions of all children with antimicrobial activity in plasma were 11.0 percent for those with fatal illness, 8.6 percent for those with severe illness, and 3.5 percent for those with nonsevere medical problems. Plasma antimicrobial activity was significantly associated with bacteremia both in patients who died (odds ratio, 0.38 ; 95 percent confidence interval, 0.15 to 0.98 ) and in those who had severe illness (odds ratio, 0.27; 95 percent confidence interval, 0.08 to 0.92 ) but not in those with nonacute medical problems.

\section{TYPES OF BACTEREMIA}

A single organism was isolated from each of 1057 cultures obtained on admission, two organisms were isolated from each of 36 cultures, and three organisms were isolated from 1 culture. Thus, 1132 organisms were isolated from 1094 admission blood cultures (Table 2).

Among children who were at least 60 days of age, Streptococcus pneumoniae, nontyphoidal salmonella, $H$. influenzae, and Escherichia coli accounted for more than 70 percent of isolates. The proportion of the cases of bacteremia that were caused by either S. pneumoniae or S. aureus increased with each year

\begin{tabular}{|c|c|c|c|c|c|c|c|}
\hline \multirow[t]{2}{*}{ Age } & \multirow[t]{2}{*}{$\begin{array}{c}\text { All } \\
\text { Patients }\end{array}$} & \multicolumn{2}{|c|}{$\begin{array}{l}\text { Patients with } \\
\text { Bacteremia }\end{array}$} & \multicolumn{2}{|c|}{$\begin{array}{l}\text { Patients without } \\
\text { Bacteremia }\end{array}$} & \multirow[t]{2}{*}{$\begin{array}{l}\text { Patients with } \\
\text { Bacteremia } \\
(95 \% \mathrm{Cl})\end{array}$} & \multirow[t]{2}{*}{$\begin{array}{l}\text { Deaths Involving } \\
\text { Bacteremia } \\
(95 \% \mathrm{Cl})\end{array}$} \\
\hline & & Total & Deaths & Total & Deaths & & \\
\hline & & & & & & \multicolumn{2}{|c|}{ percent } \\
\hline$<7$ days & 867 & 117 & 65 & 750 & 247 & $13.5(11.5-16.0)$ & $20.8(16.5-25.8)$ \\
\hline $7-59$ days & 916 & 111 & 29 & 805 & 51 & $12.1(10.1-14.4)$ & $36.2(25.8-47.8)$ \\
\hline 60-364 days & 4,354 & 301 & 86 & 4,053 & 152 & $6.9(6.2-7.7)$ & $36.1(30.0-42.5)$ \\
\hline$\geq 1 \mathrm{yr}$ & 10,433 & 565 & 128 & 9,868 & 426 & $5.4(5.0-5.8)$ & $23.1(19.7-26.8)$ \\
\hline All ages & 16,570 & 1094 & 308 & 15,476 & 876 & $6.6(6.2-7.0)$ & $26.0(23.5-28.6)$ \\
\hline
\end{tabular}

* Cl denotes confidence interval. 
of age. S. pneumoniae was found in 26 percent of patients who were 12 to 23 months old and in 49 percent of patients who were more than 5 years old. S. aureus was found in 3 percent of patients who were 12 to 23 months old and in 14 percent of patients who were more than 5 years old $(\mathrm{P}<0.001)$. The proportion of patients with nontyphoidal salmonella declined from 23 percent among those who were 12 to 23 months old to 7 percent among those who were more than 5 years old $(\mathrm{P}<0.001)$. $H$. influenzae continued to account for 11 percent of isolates in patients who were at least five years old. In infants under 60 days of age, the most common bacterial species were E. coli (in 13.7 percent of isolates), group B streptococci (in 10.8 percent), and acinetobacter species (in 10.4 percent) (Table 2). Pneumococci, S. aureus, group A streptococci, and klebsiella species each accounted for approximately 8 percent of isolates in young infants.

Two isolates of $S$. pneumoniae and one of $H$. influenzae could not be propagated in culture for serotyping. The most common pneumococcal serotypes were 1 (in 66 patients), 14 (in 39), 6A (in 26), 6B (in 24), $23 \mathrm{~F}$ (in 21), 18C (in 13), 4 (in 11), 3 (in 10), and 19F (in 10). Of 18 isolates from young infants, 11 were of serotypes contained in the 9-valent conjugate pneumococcal vaccine (61.1 percent); of 262 isolates from older children, 185 were of serotypes contained in the pneumococcal vaccine (70.6 percent). ${ }^{18}$ Among isolates of $H$. influenzae, 113 of 136 were serotype $b$ ( 83.0 percent), including 5 of 8 isolates from young infants; 15 isolates could not be typed (11.2 percent), 5 were serotype $f$, and 2 were serotype a.

\section{INCIDENCE OF COMMUNITY-ACQUIRED BACTEREM IA}

The minimal incidence of community-acquired bacteremia was 1457 cases per 100,000 children per year for children under one year of age, 1080 per 100,000 per year for those under two years, and 505 per 100,000 per year for those under five years (Table 3). The minimal rate of neonatal bacteremia was 5.46 cases per 1000 live births. For comparison,

\begin{tabular}{|c|c|c|c|c|c|c|}
\hline \multirow[t]{3}{*}{ Pathogen } & & & Age & & \multirow{3}{*}{$\begin{array}{c}\text { Total } \\
\text { (All Ages) }\end{array}$} & \multirow[t]{3}{*}{$\begin{array}{c}\text { Rank of } \\
\text { Incidence }\end{array}$} \\
\hline & $<7$ Days & 7-59 Days & 60-364 Days & $\geq 1 \mathrm{Yr}$ & & \\
\hline & \multirow{2}{*}{\multicolumn{5}{|c|}{ number of isolates (percent)* }} & \\
\hline Gram-positive & & & & & & \\
\hline Streptococcus pneumoniae & $5(4)$ & $14(12)$ & $63(20)$ & $200(34)$ & 282 & 1 \\
\hline Staphylococcus aureus & $7(5)$ & $13(12)$ & $17(5)$ & $41(7)$ & 78 & 5 \\
\hline Group A streptococci & $3(2)$ & $17(15)$ & $10(3)$ & $18(3)$ & 48 & 7 \\
\hline Group B streptococci & $11(9)$ & $15(13)$ & 0 & $2(<1)$ & 28 & 10 \\
\hline Other' & $11(9)$ & $3(3)$ & $11(4)$ & $11(2)$ & 36 & - \\
\hline \multicolumn{7}{|l|}{ Gram-negative } \\
\hline Nontyphoidal salmonella species & $1(<1)$ & $4(4)$ & $56(18)$ & $105(18)$ & 166 & 2 \\
\hline Haemophilus influenzae & $1(<1)$ & $7(6)$ & $62(20)$ & $66(11)$ & 136 & 3 \\
\hline Escherichia coli & $25(19)$ & $8(7)$ & $41(13)$ & $47(8)$ & 121 & 4 \\
\hline Acinetobacter species & $16(12)$ & $9(8)$ & $16(5)$ & $30(5)$ & 71 & 6 \\
\hline Pseudomonas species & $6(5)$ & $3(3)$ & $15(5)$ & $15(3)$ & 39 & 8 \\
\hline Klebsiella species & $13(10)$ & $7(6)$ & $7(2)$ & $9(2)$ & 36 & 9 \\
\hline Other: & $30(23)$ & $12(11)$ & $12(4)$ & $37(6)$ & 91 & - \\
\hline Total & 129 & 112 & 310 & 581 & $1132 \pi$ & \\
\hline
\end{tabular}

* Percentages refer to the proportion of the isolates in each age group. Percentages may not sum to 100 because of rounding. $\dagger$ Species included streptococci groups D (27 patients), C (3), and G (6).

$\nmid$ Species included enterobacter (22 patients), aeromonas (13), campylobacter (9), citrobacter (7), Proteus mirabilis (7), shigella (6), and neisseria (5)

$\int$ Since polymicrobial bacteremia was identified in 37 patients, the number of isolates exceeds the number of patients. 


\begin{tabular}{|c|c|c|c|c|}
\hline \multirow[t]{3}{*}{ Pathogen } & \multicolumn{4}{|c|}{ Incidence of Bacteremia* } \\
\hline & $\begin{array}{c}<28 \text { Days Old } \\
(\mathrm{N}=27,284 \text { Births })\end{array}$ & $\begin{array}{l}<1 \mathrm{Yr} \text { Old } \\
(\mathrm{N}=26,968 \\
\text { Person-Yr) }\end{array}$ & $\begin{array}{l}<2 \mathrm{Yr} \text { Old } \\
(\mathrm{N}=50,804 \\
\text { Person-Yr) }\end{array}$ & $\begin{array}{c}<5 \mathrm{Yr} \text { Old } \\
(\mathrm{N}=136,444 \\
\text { Person-Yr) }\end{array}$ \\
\hline & $\begin{array}{c}\text { no./1000 live } \\
\text { births/year }\end{array}$ & \multicolumn{3}{|c|}{ no. $/ 100,000$ children $/$ year } \\
\hline Any organism & 5.46 & 1457 & 1080 & 505 \\
\hline Streptococcus pneumoniae & 0.37 & 241 & 213 & 111 \\
\hline Staphylococcus aureus & 0.44 & 89 & 57 & 27 \\
\hline Group A streptococci & 0.55 & 96 & 63 & 29 \\
\hline Group B streptococci & 0.66 & 74 & 39 & 15 \\
\hline Nontyphoidal salmonella species & 0.07 & 170 & 175 & 88 \\
\hline Haemophilus influenzae & 0.07 & 159 & 120 & 60 \\
\hline Escherichia coli & 0.81 & 204 & 136 & 54 \\
\hline
\end{tabular}

* Person-years of observation are shown for patients under the age of one year, two years, and five years, calculated as the midstudy population multiplied by four years.

among children under the age of five years, the incidence of admission to the hospital with a diagnosis of malaria was 3893 admissions per 100,000 per year, and the incidence of admission with a diagnosis of gastroenteritis was 2057 per 100,000 per year.

\section{HIV INFECTION AND MALNUTRITION}

HIV infection was present in 186 of 1044 patients with bacteremia (17.8 percent) and in 57 of 1037 patients who did not have bacteremia (5.5 percent) $(\mathrm{P}<0.001)$. Severe malnutrition was present in 410 of 1094 patients with bacteremia (37.5 percent) and in 3341 of 15,476 patients who did not have bacteremia (21.6 percent) $(\mathrm{P}<0.001)$. Both HIV infection and malnutrition were independently associated with bacteremia (Table 4). There was no evidence of an interaction between the effects of HIV infection and malnutrition on bacteremia $(\mathrm{P}=0.36)$.

\section{IN PATIENT MORTALITY}

Of a total of 1094 patients who had bacteremia, 308 died (28.2 percent), as compared with 876 of 15,476 patients who did not have bacteremia (5.7 percent) $(\mathrm{P}<0.001)$. The case fatality rate did not vary significantly among the bacterial isolates. Overall, 308 of all 1184 inpatient deaths (26.0 percent) were associated with bacteremia (Table 1 ). For comparison, 258 deaths (21.8 percent) were associated with P. falciparum parasitemia. Of those deaths, 53 were in infants and children with bacteremia $(20.5$ percent).

Deaths in children with bacteremia were rapid: 103 of 308 deaths occurred on the day of admission (33.4 percent), 79 occurred the next day (25.6 percent), and 35 occurred on day 3 (11.4 percent). The predominant isolates among children who died on the day of admission were $S$. pneumoniae (49 percent) and $H$. influenzae (19 percent) in patients who were at least 60 days old and group B streptococci (13 percent), E. coli (11 percent), and klebsiella species (11 percent) in younger children.

\section{DISCUSSION}

The stimulus for this study was the observation that inpatient deaths in Kilifi usually occurred after a febrile illness. Although the area has a high rate of malaria, the disease was associated with less than a quarter of the deaths, ${ }^{19}$ and there were few data on other causes. We found that community-acquired bacteremia was responsible for at least one third of deaths in infants and one quarter of deaths in children over one year of age.

Several factors suggest that our incidence figures considerably underestimate the actual incidence of bacterial sepsis. First, it is well established that blood cultures are insensitive for detecting bacteremia. In a series of 815 children with clinically defined sepsis in Latin America, only 26 percent 
were found to have positive blood cultures, although the mortality among the children who had positive blood cultures was equivalent to that among the children who had negative cultures. ${ }^{20}$ In neonates with septicemia, the incidence of group B streptococcal infection may be underestimated by more than 50 percent if positive cultures from sites other than blood are not considered. ${ }^{21}$

Small volumes of inoculation and the use of antibiotics may compromise the sensitivity of blood cultures. ${ }^{22}$ We found that the sensitivity of blood cultures fell by almost one third when cultured samples of $1 \mathrm{ml}$ were compared with those of $3 \mathrm{ml}$. Recent antibiotic use reduced blood-culture yields by 62 to 73 percent in patients with severe or fatal disease. Ten percent of such patients had evidence of recent antibiotic use, but it is likely that many more patients had been exposed to antibiotics in the few days preceding admission. Children who died during the study had the lowest-volume blood samples for culture and the greatest rate of antibiotic use and were therefore the most susceptible to these types of underascertainment.

Second, in common with most rural areas of sub-Saharan Africa, 66 percent of deaths of children between the ages of three months and five years in our surveillance area occur outside hospitals (unpublished data). It is quite conceivable, therefore, that the true community-based incidence of bacteremia is at least twice the rate that we observed. For all of these reasons, there is likely to have been a large burden of undetected bacteremia with additional attributable mortality. Seen in this context, our findings suggest that invasive bacterial infection is the principal immediate cause of death among children admitted to Kilifi District Hospital and makes a significant contribution to community-based mortality among children in this rural, sub-Saharan district.

In children who were at least 60 days of age, S. pneumoniae and nontyphoidal salmonella species were the predominant isolates, supporting results from other African series. ${ }^{3,4,7,9-11}$ We found only three cases of Neisseria meningitidis and one case of Salmonella typhi bacteremia. H. influenzae type b conjugate vaccination was introduced in the final eight months of the study. We did not observe any effect within this period and believe that our results accurately reflect the prevaccination era. Our findings in young infants appear to differ from those of the WHO multicenter study, ${ }^{23}$ which reported that S. pneumoniae, S. aureus, and group A streptococci

\begin{tabular}{|lcc|}
\hline \multicolumn{3}{|l|}{$\begin{array}{l}\text { Table 4. Odds Ratio for Community-Acquired Bacteremia in Children } \\
\text { with Malnutrition and Those with HIV Infection. }\end{array}$} \\
\hline \multicolumn{3}{|c|}{ Odds Ratio (95\% Confidence Interval)* } \\
Pathogen & Malnutrition & HIV Infection†' \\
Nonet & 1.00 & 1.00 \\
Any organism & $2.02(1.65-2.47)$ & $3.22(2.34-4.44)$ \\
Streptococcus pneumoniae & $1.85(1.36-2.52)$ & $5.84(3.98-8.56)$ \\
Staphylococcus aureus & $1.31(0.76-2.26)$ & $1.93(0.87-4.27)$ \\
Group A streptococci & $3.28(1.75-6.15)$ & $2.24(0.82-6.14)$ \\
Group B streptococci & $1.15(0.45-3.00)$ & - \\
Nontyphoidal salmonella species & $1.68(1.15-2.44)$ & $3.21(1.95-5.28)$ \\
Haemophilus influenzae & $1.16(0.75-1.79)$ & $2.97(1.71-5.17)$ \\
Escherichia coli & $4.73(3.15-7.10)$ & $2.24(1.19-4.22)$ \\
\hline
\end{tabular}

* Odds ratios are for the presence or absence of bacteremia, adjusted for age, HIV infection, and malnutrition.

$\dagger$ Data regarding the status of infection with HIV were missing for 50 patients with bacteremia (4.6\%), so only 1044 patients were included in the analysis. $\checkmark$ A total of 1037 patients were randomly selected and matched by age and by the severity of their illness to patients with bacteremia.

$\int$ HIV infection was not detected in any patients with group B streptococcal bacteremia.

predominated and that group B streptococcal infections were uncommon. We found that group B streptococcal bacteremia was the leading bacterial cause of early death in young infants. This difference in findings partly reflects the designs of the two studies: the WHO study included only infants who were under three months of age, of whom 8 percent were recruited during the first week of life; of the patients in our study who were under three months of age, 40 percent (867 of 2172) were less than a week old. The prevalence of HIV infection among women attending the hospital antenatal clinic $(9.8$ percent) is close to the World Bank's overall estimate of 9.3 percent for sub-Saharan Africa in $2001 .^{24}$ Our findings are likely to reflect the situation in the region as a whole. Although HIV infection was an important risk factor, 82 percent of the patients in our study who had community-acquired bacteremia were not infected with HIV.

The considerable mortality associated with community-acquired bacteremia and the short interval between admission and death, despite careful implementation of the WHO recommendations for treatment, highlight the need for prevention. Even where microbiologic facilities exist, causative organisms can be identified only after 24 to 48 hours, by which time most deaths in children with bacteremia have already occurred.

In countries in which $H$. influenzae type $\mathrm{b}$ and 
pneumococcal conjugate vaccines have been introduced in infancy, there has been a dramatic reduction in severe illness caused by these organisms. ${ }^{18,25,26}$ With the support of the Global Alliance for Vaccines and Immunization, seven African countries had introduced $H$. influenzae type $b$ conjugate vaccine into routine immunization services by December 2003. Conjugate pneumococcal vaccine has not been used in Africa except in efficacy trials, although the Pneumococcal Vaccines Accelerated Development and Introduction Plan is working to establish pneumococcal surveillance and promote vaccination.

We believe that the principal reason for the failure to prioritize the introduction of available vaccines is the widespread perception that these diseases have only marginal significance in public health. For instance, invasive bacterial infection does not specifically appear on the basic lists produced by the WHO and other agencies regarding the major causes of death in children in sub-Saharan Africa (i.e., malnutrition, acute respiratory infection, diarrhea, malaria, measles, HIV infection, and perinatal conditions). ${ }^{1,27}$

The WHO estimates that 77 percent of the 4.6 million deaths ${ }^{1}$ in children under the age of five years in sub-Saharan Africa each year are nonperinatal. ${ }^{27}$ In this study, 4.9 percent of hospital deaths in children between the ages of 60 days and 5 years were attributable to $H$. influenzae bacteremia, and 8.7 percent to $S$. pneumoniae bacteremia. If these proportions were extrapolated across sub-Saharan Africa to include all children under the age of five years, these two organisms would account for a minimum of 482,000 annual deaths, the majority of which could be prevented with the use of available vaccines. Although this study provides evidence of an enormous potential benefit of existing bacterial vaccines, there are no corresponding published studies of costs or cost-benefit ratios in this setting. Overcoming the political and financial barriers to widespread implementation of existing vaccines and developing new vaccines against other common bacterial pathogens are among the most urgent priorities for increasing the survival of children in sub-Saharan Africa.

Supported by the Kenya Medical Research Institute and by the Wellcome Trust.

We are indebted to the medical officer of health, the hospital superintendent, the clinicians, the clinical assistants, and the nursing staff of Kilifi District Hospital; to the director of KEMRI; and to Dr. Norbert Peshu, director of the Centre for Geographic Medicine Research (Coast), for his support and guidance.
REFERENCES

1. UNICEF. The state of the world's children 2004. (Accessed November 18, 2004, at http://www.unicef.org/publications/2004_ OfficialSumm_ENG.pdf.)

2. Peltola H. Burden of meningitis and other severe bacterial infections of children in Africa: implications for prevention. Clin Infect Dis 2001;32:64-75.

3. Ghiorghis B, Geyid A, Haile M. Bacteremia in febrile out-patient children. East Afr Med J 1992;69:74-7.

4. Lepage P, Bogaerts J, Van Goethem C, et al. Community-acquired bacteremia in African children. Lancet 1987;1:1458-61.

5. Madhi SA, Petersen K, Madhi A, Wasas A, Klugman KP. Impact of human immunodeficiency virus type 1 on the disease spectrum of Streptococcus pneumoniae in South African children. Pediatr Infect Dis J 2000; 19:1141-7.

6. Karstaedt AS, Khoosal M, Crewe-Brown HH. Pneumococcal bacteremia during a decade in children in Soweto, South Africa. Pediatr Infect Dis J 2000;19:454-7.

7. Cotton MF, Burger PJ, Bodenstein WJ. Bacteremia in children in the south-western Cape: a hospital-based survey. S Afr Med J 1992;81:87-90.

8. Wolf BH, Ikeogu MO, Vos ET. Effect of nutritional and HIV status on bacteraemia in
Zimbabwean children who died at home. Eur J Pediatr 1995;154:299-303.

9. Walsh AL, Phiri AJ, Graham SM, Moly neux EM, Molyneux ME. Bacteremia in febrile Malawian children: clinical and microbiologic features. Pediatr Infect Dis J 2000;19. 312-8.

10. Bahwere P, Levy J, Hennart P, et al. Community-acquired bacteremia among hospitalized children in rural central Africa. Int J Infect Dis 2001;5:180-8.

11. O'Dempsey TJ, McArdle TF, Lloyd-Evans $\mathrm{N}$, et al. Importance of enteric bacteria as a cause of pneumonia, meningitis and septicemia among children in a rural community in The Gambia, West Africa. Pediatr Infect Dis J 1994;13:122-8.

12. AIDS in Kenya. 6th ed. Nairobi, Republic of Kenya: Ministry of Health, 2001.

13. Berkley JA, Ross A, Mwangi I, et al. Prognostic indicators of early and late death in children admitted to a district hospital in Kenya. BMJ 2003;326:361-7.

14. Management of the child with a serious infection or severe malnutrition: guidelines for care at the first-referral level in developing countries. Geneva: World Health Organization, 2000.

15. Falla TJ, Crook DW, Brophy LN, Maskel D, Kroll JS, Moxon ER. PCR for capsular typ- ing of Haemophilus influenzae. J Clin Microbiol 1994;32:2382-6.

16. Graham SM, Mtitimila EI, Kamanga HS, Walsh AL, Hart CA, Molyneux ME. Clinical presentation and outcome of Pneumocystis carinii pneumonia in Malawian children. Lancet 2000;355:369-73. [Erratum, Lancet 2000;355:850.]

17. Brown CC. The validity of approximation methods for interval estimation of the odds ratio. Am J Epidemiol 1981;113:47480.

18. Klugman KP, Mahdi SA, Heubner RE, Kohberger R, Mbelle N, Pierce N. A trial of a 9-valent pneumococcal conjugate vaccine in children with and those without HIV infection. N Engl J Med 2003;349:1341-8.

19. Marsh K, Forster D, Waruiru C, et al. Indicators of life-threatening malaria in African children. N Engl J Med 1995;332:1399404.

20. Saez-Llorens X, Vargas S, Guerra F, Coronado L. Application of new sepsis definitions to evaluate outcome of pediatric patients with severe systemic infections. Pediatr Infect Dis J 1995;14:557-61.

21. Luck S, Torny M, d'Agapeyeff K, et al. Estimated early-onset group B streptococcal neonatal disease. Lancet 2003;361:1953-4.

22. Shann F. Bacterial pneumonia: com- 
moner than perceived. Lancet 2001;357: 2070-2.

23. The WHO Young Infants Study Group. Bacterial etiology of serious infections in young infants in developing countries: results of a multicenter study. Pediatr Infect Dis J 1999;18:Suppl:S17-S22.

24. The World Bank Group. Sub-Saharan

Africa data profile. (Accessed November

18, 2004, at http://devdata.worldbank.org/
external/CPProfile.asp?SelectedCountry= SSA\&CCODE $=$ SSA\&CNAME $=$ SubSaharan + Africa\&PTYPE $=$ CP.)

25. Whitney CG, Farley MM, Hadler J, et al.

Decline in invasive pneumococcal disease

after the introduction of protein-polysaccharide conjugate vaccine. $\mathrm{N}$ Engl J Med 2003;348:1737-46.

26. Mulholland K, Hilton S, Adegbola R, et al. Randomised trial of Haemophilus influ- enzae type-b tetanus protein conjugate vaccine for prevention of pneumonia and meningitis in Gambian infants. Lancet 1997;349: 1191-7. [Erratum, Lancet 1997;350:524.]

27. World Health Organization. Proportional mortality among under fives, worldwide 2001. (Accessed November 29, 2004 at www.who.int/child-adolescent-health/ overview/child_health/map_01_world.jpg.) Copyright (c) 2005 Massachusetts Medical Society. 